\title{
Exploring the Effect of Frictional Heat on Rate of Fuel Combustion by ICE through Modeling and Simulation with Reference to ICE Parameters.
}

\author{
Motey Festus
}

\author{
Dr. Essel Ben Hagan
}

\begin{abstract}
Otto cycle operations of ICEs have relatively higher capacities and efficiency. Factors of efficiency, emission, fuel consumption and output power are considered during design and construction of ICEs. Engine size, engine weight, number of pistons, swept volume, cylinder arrangement and number of valves all differs in accordance to type of ICE. Fundamental principle of ICE is burning of air - fuel mixture of appropriate proportions in air tight chamber to produce heat energy for motion. Fossil fuel of diesel and gasoline obtained from underground are the main fuels used by ICEs. The engine block houses cylinders, pistons rings, connecting rods and pistons. At top seals of cylinders are located inlet valves, outlet valves and channels. Crankcase houses crankshaft and bearings whiles the sump serves as reservoir for lubrication oil. Lubrication oil also known as lubricant reduces friction between moving surfaces in ICEs through piston ring grooves. Connecting rod is the linkage between crankshaft and piston. Gudgeon - pin transmits combustion force from piston to connecting rod then to crankshaft. Thus, crankshaft converts reciprocating motion of piston to cyclic motion. During operations of ICEs, friction occurs between pistons with piston rings collectively and inner walls of cylinder. Frictional effects account for about thirty five percent (35\%) of total heat generated in ICEs. The methodology adopted by this article is modeling and simulating frictional models by previous authors. These models were incorporated with ICE parameters before modeling and simulation again. Objectively, graphical results show reduction in heat generation due to friction.
\end{abstract}

Key words: Blowby, Lubricant, Friction, Combustion, Simulation.

NOMENCLATURE

BDC or ODC

HDDE

ICE

PRCL

TDC or IDC

\author{
Bottom Dead Center \\ Heavy Duty Diesel Engine \\ Internal Combustion Engine \\ Piston Ring Cylinder Liner \\ Top Dead Center
}

\section{INTRODUCTION}

The ratio of power to weight is far higher when using the Otto cycle principle as compared to capabilities of steam engine operations. Relatively, the Otto cycle have better capabilities in terms of operations and efficiency when used for a lot of transportation applications like aircraft, vehicles, among others. The four stroke Otto cycle engine produced by Karl Benz has led to the development of more powerful ICEs, particularly for automobiles such as trucks, buses and cars. Heavy weight diesel engines are normally used in trucks and buses. Relatively, the four stroke Otto cycle light weight gasoline ICEs are mostly used in automobiles such as cars. Ganeshan, (2012). During the design and construction of the automobile engines, factors such as efficiency, emissions and affordability are taken into consideration. These engines have varieties of power ratings, thus from low power output to very high power output values. 
There are also variations in engine size, weight, number of cylinders, volumetric displacement, cylinder arrangements and valves. Livanos and Kyrtatos, (2006).

The fundamental principles of ICE is the exclusive burning of fuel in fluid form in a confined chamber with oxygen. Normally, the liquid fuels that are burnt during the combustion in ICEs are gasoline or petrol and diesel. Air - fuel mixture in the right quantities are introduced and compressed in the combustion chamber before igniting to burn. Tamminen, Sandstroma and Anderson, (2006). This internal combustion results to release of heat energy at high gas pressures which is useful for forcing the piston to move along the stroke length in cylinder. This is useful mechanical work resulting from internal combustion. Piston energy is transmitted by connecting rod to crankshaft. The objective of this research or article is to analyze frictional heat effect on rate of fuel consumption through modeling and simulation with reference to engine parameters such as piston diameter, number of piston rings, number of pistons and weight of connecting rod. Rupp, (2009).

\section{Engine Structure and Functions}

\section{REVIEWED LITERATURE}

The cylinder or engine block is a structure obtained from casting. This block has bores which serve as control for working gases, provides support for piston as well as piston rings. The block also houses channels or galleries through which coolant flows. The top of combustion chamber is enclosed by cylinder head and this is also top of cylinder block. This head houses inlet valves, outlet valves, inlet ports and other fluid channels. Crankcase is produced from casting. Functions of crankcase are housing and supporting crankshaft as well as bearings. Crankcase is also mono - constructional structure casted with cylinder block. This structure is produced from casting of steel or aluminum alloy. Sahoo, (2011).

The sump serves as reservoir that accommodates lubrication oil. Lubricating oil or lubricant is pumped from sump to moving metal surfaces in contact to reduce friction. Piston functions by converting pressure from very hot gases to concentrated forces of driving at connecting rod. Thus, the piston is a plunge which is cylindrical in shape and pressure tight. Repeated up and down motion of piston is referred to as reciprocating motion and it is linear motion. The gaps or spaces between inner cylinder walls and outer surface walls of piston are sealed by special circular rings called piston rings. These rings function by stopping the movement of gases and lubricant between these walls. Mufti, (2004). The gudgeon pin is responsible for transmission of force or pressure from piston to connecting rod small end. This pin allows rotational or cyclic motion of crankshaft. Connecting rod transmits linear motion of piston to crankshaft. Crankshaft converts linear motion to cyclic motion. This crankshaft is made of circular sectional shaft that is cranked or bent into two right angled crank - arms as well as an offset big end journal. The main journal is unbent section of this crankshaft. Priest and Taylor, (2002). Connecting rod serves as linkage between crankshaft and piston. This linkage caters for conversion of linear reciprocating motion to circular or rotary motion. Crankshaft journals are finished cylindrical pins that are machined parallel on central as well as offset axes of crankshaft. These journals rotate in bearings mounted in main journals or crankcase as well as the big - end journal or connecting rod. Karkamkar, (2013). There exist hinged joint by gudgeon - pin between piston and connecting rod which is known as small - end. This small end enables connecting rod to oscillate relative to cylinder axis and reciprocating cylinder motion.

Big - end enables relative angular motion. Rubbing pair occurs between crankshaft main journal and their corresponding plain bearings that are mounted in crankcase. Line stroke is at center path which piston is compelled to follow as a result of constraints of cylinder. The piston 
is at either one of it's two positions of extreme if connecting rod and crank arm are aligned along line of stroke. When piston is at closest point or location to cylinder head, then piston and crank are at IDC or TDC. However, if piston is at longest distance away from cylinder head, then both crank and piston are at ODC or BDC. Sandoval and Heywood, (2003). These reference centers are useful for ignition settings leading to valve crankshaft timing. Clearance volume or combustion chamber space is the allowance or space between piston crown at TDC and cylinder head. Crank - throw is distance from center of big - end journal to center of crankshaft main journal. Piston stroke is distance covered or movement from IDA to ODC. Piston stroke is equivalent to half crankshaft rotation or twice crank - throw or one hundred and eighty (180) degrees. Sand scores which occupy cylinder spaces of engine block are used to cast cylinder bore. These bores are machined to be smooth after sand scores are removed which includes boring. Cho, Choi and Bae, (2000).

\section{Friction and Heat Generation}

ICEs or automobile engines experience losses of mechanical energy due to friction between inner cylinder walls and piston as well as piston rings. High application of HDDE in the transport industry makes it interesting researching into it's efficiency. Approximately, only about fourty percent (40\%) of fuel energy is utilized by HDDE as mechanical power for motion. The rest of fuel energy content is lost through friction, thermal energy resulting from friction, among others. Bedajangam and Jadhave, (2003).

Highest of these losses occur due to frictional effect between inner cylinder walls and piston with piston rings. This frictional effect results to heat generation within ICEs. Reduction of this friction will result to reduction in fuel consumption, specifically diesel consumption as well as increase in efficiency of ICE or HDDE. Normally, PRCL pack has three (3) piston rings but some relatively bigger ICEs have four piston rings. Law, (2007). Each of these piston rings has their respective shapes in - accordance to their functions. These piston rings are made from cast iron and identified as upper compression ring, lower compression ring as well as oil control ring. Upper compression ring is coated with electrochemical chromium on the running surface in order to resist wear and tear. Herst, (2007). After casting, surfaces of these piston rings are accurately smoothen by horning process. There are grooves on piston rings which function by controlling the quantity of lubricant required to reduce friction. Another function of piston rings is to prevent flow of debris so as to protect smooth surfaces from scratch and damage. The function of upper compression ring is to seal unwanted spaces between inner cylinder walls and piston as well as piston rings. Additional sealing and scraping of lubricant flowing downwards are functions of lower compression ring. Zoz, Strepek, Wiseman, and Qian, (2001).

The oil control ring works as main barrier or blockage between starved lubricated region of ring belt and well lubricated piston skirt area. Increasing contact temperature in spaces and lubricant velocity are to a large extent been influenced by temperature of cylinder liner. Along axial length of cylinder liner, increasing cylinder temperature varies between ninety and two hundred (90 and 200) degree celsius. Lubrication regime and pressure of spaces varies along cylinder liner. Blowby and oil consumption, wear as well as frictional power losses are most important factors to be considered for reducing frictional effects on PRCL contact in ICEs. Zammit, (2013). Overall efficiency will improve upon lowering of above factors. Combustion gases which flow from combustion chamber and by pass piston rings will enter crankcase. As a result, these gases will cause power losses as well as lower efficiency and are referred to as blowby. Piston motion occurs many times per second which is an indication that high losses occur during ICE operations. Conditions of proper ICE operations will have gases strictly confined to combustion chamber whiles lubricant is restricted to it's galleries and sump. Space 
between ring groove and flank of ring can be channels for blowby. Reducing blowby results to reducing volumetric power losses. This research is conducted for all regimes of lubrication. Yildiz, Annaswamy, Yanakiev, and Kolmanovsk, (2010).

\section{METHODOLOGY}

The methodology adopted for this research is modeling and simulation. The models are mathematical representations of operations or parts of ICEs. Matlab is the tool which contains modeling and simulation. When this tool is opened, modeling command window also opens. This command window contains tools for modeling. Also, modeling involves writing of matlab programs using parameters of specific models. Thus, these variables or parameters and constants of models must be the only variables as well as constants to be used in programming. Modeling begins with writing of topic or title which reflects on objective of model. Samhaber, Wimmer and Liobner, (2012). Next step of line is to write mathematical equations or expressions of models. These models are picked from literature of previous authors that are closely related to this research. These models are rewritten or revised by addition of more parameters or variables so as to cause changes in trends. Next lines of matlab programming are made of comments of definitions or explanations of terms that are used in equations or models. These comments are identified or begin with percentages (\%) which are assumed to be ignored by programs. After this, next set of lines consists of model variables equated to their respective constant values. Guzzella and Onder, (2010).

These constant values are obtained from literature of previous similar researches. Next line is made of independent variables been equated to their value ranges. On next step of line is the new independent variable which will alter this model for improvement. Subsequent lines contain equations of models from literature and modified versions respectively. Specifications of plot graph parameters such as axis labels, title of graphs and graph line legends or identifications are contents of next lines sequentially. Click on run icon to show graphs automatically. A resultant graphical line is obtained with dependent variable on vertical axis and independent variable on horizontal axis. Gilat, (2004).

At top of matlab program window is an extra toolbox which is referred to as simulink. Thus, simulink is one of the programs that run in matlab. Act of running simulink program is known as simulation. When the word simulink is typed and enter key is pressed, simulink window opens. Alternatively, simulink icon on top of matlab window can be clicked for simulink window to open. Simulink library browser will open in this window which contains main simulink block libraries as well as additional blocksets. Meyer, (2007). These libraries and blocks contain simulink blocks which are commonly used, continuous, discontinuities, discrete, logic and bit operations, lookup tables, math operations, model verification, model - wide utilities, ports and subsystems, signal attributes, signal routing, sinks, sources, user - defined functions, additional math and discrete as well as neural network toolbox blocks. These blocks are clicked on and dragged into a new window in - accordance to type of equations. Tan and Ripin, (2011). Double clicking on each of these blocks will lead to opening of function block parameters of each of these blocks. These function blocks have specific spaces for which values of parameters will be entered for model specifications. Click on "OK" to close the function block parameters. To connect blocks, click on output of earlier block and drag it to input of block to be connected or ahead. Step block is overall input and scope gives overall output graph when double clicked. Samhaber, Wimmer and Liobner, (2012). 


\section{Brake Mean Effective Pressure}

\section{EQUATIONS}

\section{Equation 108}

$$
\text { bmep }=\frac{P \times z}{V_{d} \times n}
$$

Source: Kanne, 2000.

The equation above represents a model for brake mean effective pressure of ICE.

Where

$V_{d}=$ Displaced cylinder volume

$\mathrm{s}=n=$ Rotational speed

$Z=$ Number of crank revolutions per power stroke

$P=$ Power of engine.

Burn Fraction Variation

\section{Equation 109}

$$
X_{b}(\theta)=1-\exp \cdot\left[-a\left(\frac{\theta-\theta^{n}}{\theta^{d}}\right)\right]
$$

Source: Karkamkar, (2013).

This equation above is a model for determining the fraction of unburnt fuel.

Where

$X_{b}(\theta)=$ burn fraction as a function of crank angle

$\theta=$ crank angle

$\theta_{s}=$ spark timing

$\theta^{d}=$ duration of heat release

$n=$ Weibe form factor

$a=$ Weibe efficiency factor

$$
\begin{aligned}
& a=5 \\
& n=3
\end{aligned}
$$

Load Dynamics

$$
\theta_{s}=-p i / a
$$

\section{Equation 121}

$$
P_{b}(n)=K_{b} n^{3}
$$

Source: Amini, Mirzeai Khoshbakhti Saray, (2013).

This equation above is a model for engine load.

Where:

$$
\begin{aligned}
& K_{b}=\text { engine load } \\
& n=\text { engine speed RPM } \\
& P_{b}= \\
& \mathrm{A}=\text { age } \\
& \mathrm{V}=\text { velocity } \\
& \text { Mass Flow Rate }
\end{aligned}
$$


Equation 122

$$
m=D M \frac{1}{B} a A
$$

\section{Source: Martinez, Samchez, Bermudex and Riesco-Avila, (2010)}

Equation (122) one hundred and twenty two above is a model for the mass flow rate of fuel. Where

$\mathrm{V}=$ velocity

$A=$ frontal area

$\mathrm{a}=$ sonic velocity

$\mathrm{P}=$ pressure

$\mathrm{B}=$ bore diameter

Piston Velocity

\section{Equation 129}

$$
V=S / 2 \cos \theta+\left(C^{2}-S / 2 \sin \theta\right)^{2}
$$

Source: Saris and Philips, (2005).

Equation (129) one hundred and twenty nine above is a model for piston velocity of ICE.

Where

$\mathrm{V}=$ piston velocity

$\mathrm{C}=$ rolling resistance constant

$\mathrm{S}=$ stroke length

$\mathrm{T}=$ engine temperature

$\theta=$ crank angle of piston

Rolling Resistance

\section{Equation 130}

$$
R_{r}=9.8066 \times C_{r} \times\left(C_{2} V+C_{3}\right) \times \frac{M}{1006}
$$

Source: Yue, (2008).

Equation (130) one hundred and thirty above is a model representing aerodynamic resistance. Where:

$R_{r}=$ rolling resistance $(\mathrm{N})$

$\mathrm{M}=$ vehicle mass

$\mathrm{V}=$ vehicle speed

$C_{r}, C_{2}, C_{3}=$ rolling resistance constants

\section{MODELING OF THE EQUATIONS}

Matlab Program for Equation (108) One Hundred and Eight.

OMODELING FUEL CONSUMPTION REDUCTION IN TERMS OF THERMOMANGEMENT

○BRAEK MEAN EFFECTIVE PRESSURE

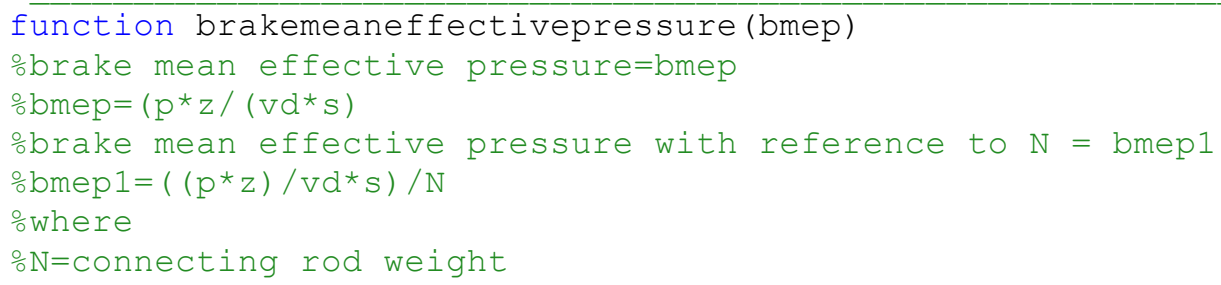




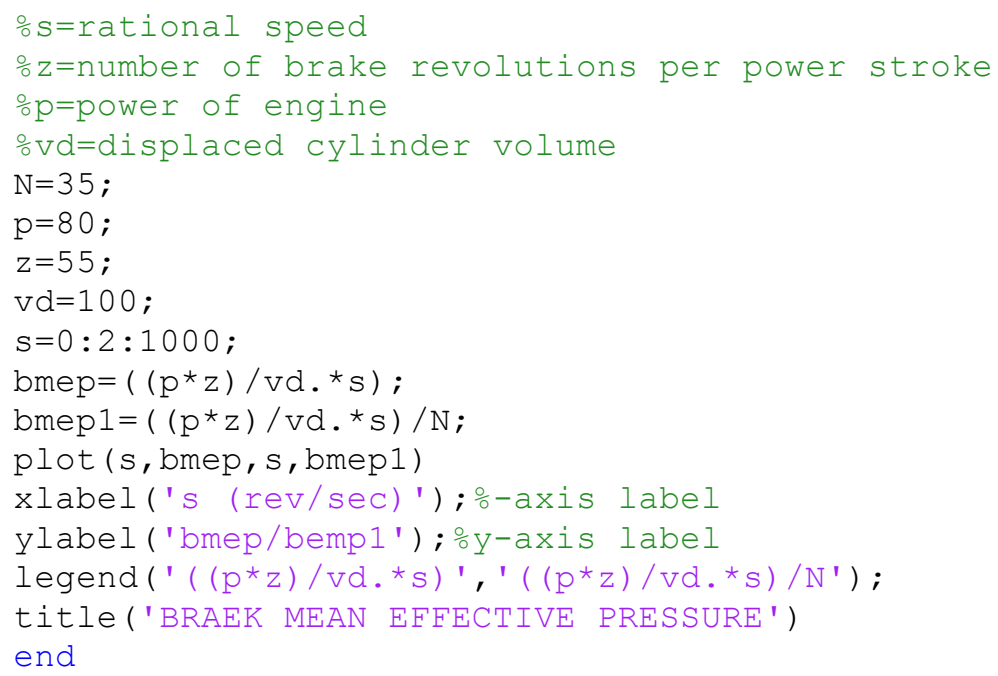

The equation" bmep" has been modified to "bmep1" by this research by incorporating $\mathrm{N}$.

\section{Matlab Program for Equation (109) One Hundred and Nine}

○SPARK TIMING ON COMBUSTION

○BURN FRACTION VARIATION

$\div$

function burnfractionvariation(xb)

$\frac{\circ \mathrm{x} b}{\mathrm{a}}=1-\exp \left(-\mathrm{a}^{*}(\text { theta }- \text { thetas/thetad })^{\wedge} \mathrm{n}\right)$

$\circ \mathrm{xb} 1=$ burn fraction variation with reference to $\mathrm{H}$

$\circ \mathrm{xb} 1=1-\exp \left(-\mathrm{a}^{*}\left(\right.\right.$ theta - thetas ${ }^{*} \mathrm{~T} /$ thetad $\left.) \wedge \mathrm{n}\right){ }^{*} \mathrm{H}$

owhere

otheta $=$ Crank angle

othetad = Duration of heat release

othetas = Spark timing

\% $\mathrm{Xb}$ is the burn fraction as a function of crank angle,

\% $\mathrm{n}$ is the Weibe form factor

\% a is the Weibe effeciency factor

$\circ \mathrm{H}$ is number of pistons

$\mathrm{n}=-5.9$;

$\mathrm{H}=7$;

$\mathrm{a}=5$;

thetad $=30 ;$

thetas $=13.7$;

theta $=0: 2: 60$;

$\mathrm{xb}=1-\exp \left(-\mathrm{a}^{*}(\right.$ theta - thetas/thetad $\left.) \cdot{ }^{\wedge} \mathrm{n}\right) ;$

$\mathrm{xb} 1=1-\exp \left(-\mathrm{a}^{\star}(\right.$ theta - thetas/thetad $\left.) \cdot{ }^{\wedge} \mathrm{n}\right){ }^{\star} \mathrm{H}$;

plot (theta, $x b$, theta, $x b 1$ )

xlabel ('theta (deg) ') ; $\circ x-a x i s ~ l a b e l$

ylabel ('xb/xbl'); y-axis label

legend (' (1-exp (-a* (theta-thetas/thetad).^n) ', ' (1-exp (-a* (theta-

thetas/thetad).^n)*H) ')

title('BURN FRACTION VARIATION')

end

The equation for " $\mathrm{xb}$ " has been modified by this research to "xb1" by incorporating $\mathrm{H}$.

Matlab Program for Equation (121) One hundred and Twenty One.

으TIMIZATION OF CONTROL LAW FOR AIR FUEL RATIO

○OAD DYNAMIC

$\%$

function loaddynamic(pbn)

-load dynamic (pbn) $=\mathrm{pb}^{\star} \mathrm{n}^{\wedge} 3$

oload dynamics with reference to $\mathrm{J}=$ pbn 1

$\circ \mathrm{pbn} 1=\mathrm{pbn} \cdot * \mathrm{~J} * \mathrm{n} \wedge 3$

$\% J=$ number of piston rings 


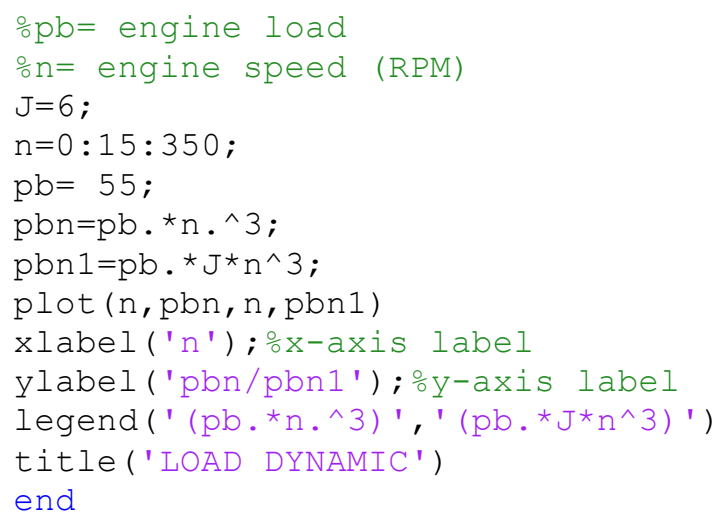

Equation "pbn" was remodeled by this research to form equation "pbn1" by multiplying or incorporating J.

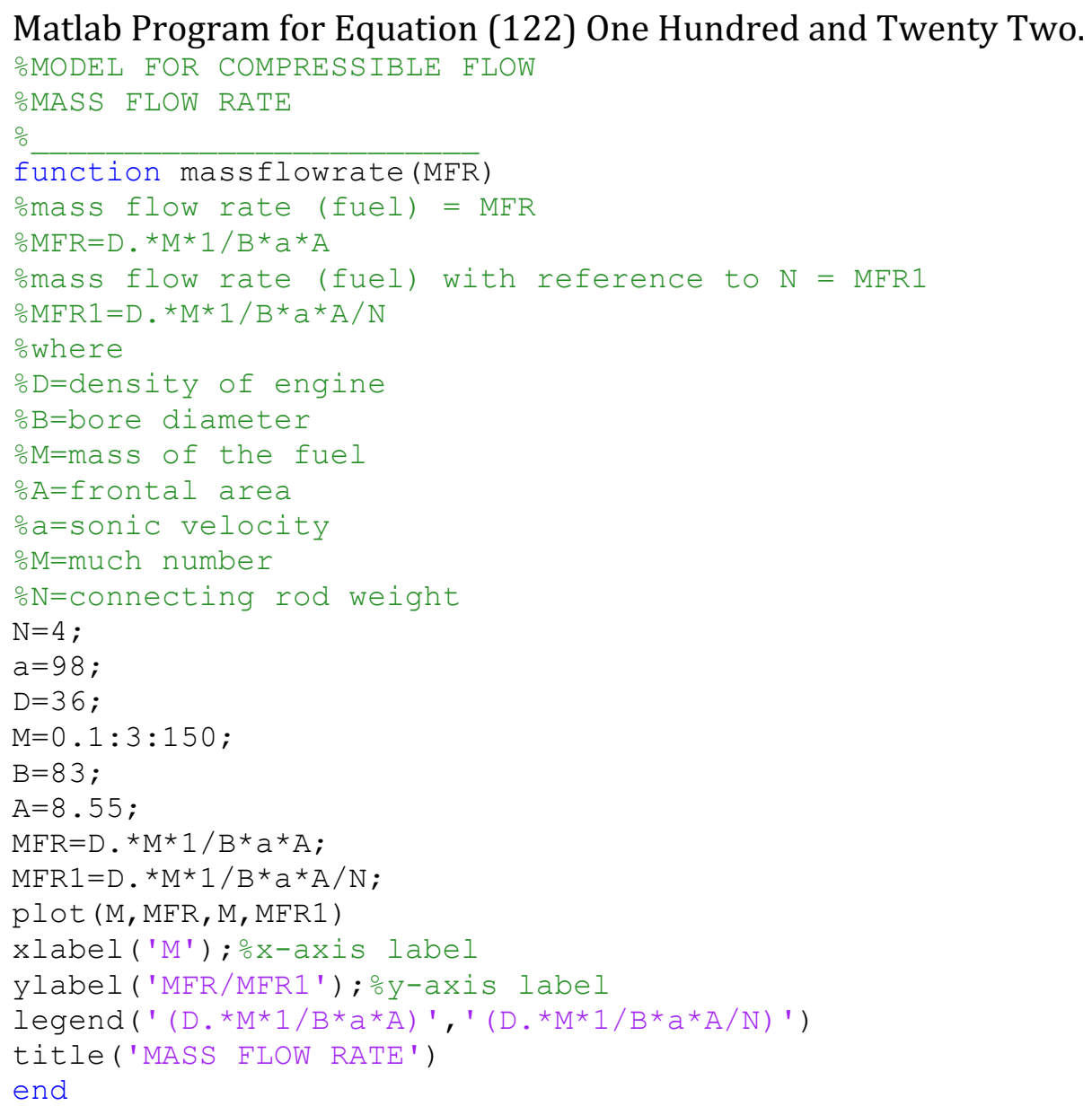

The remodeling of equation "MFR" by this research involves incorporating $\mathrm{N}$ to form the equation MFR1.

Matlab Program for Equation (129) One Hundred and Twenty Nine FLUID CHARACTERISTIC MODELING IN ICE ○PISTON VELOCITY 


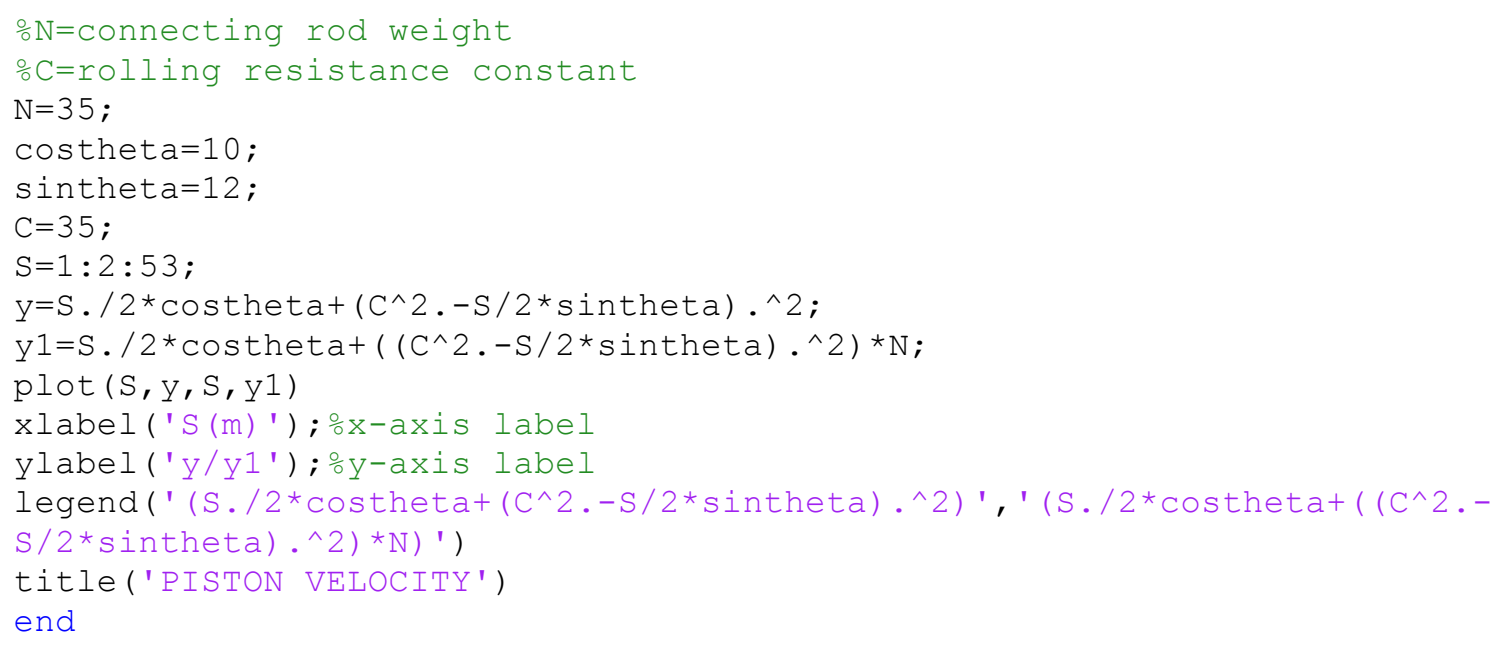

The equation " $\mathrm{y}$ " has been remodeled by this research to form equation "y1" by incorporating N.

Matlab Program for Equation (130) One Hundred and Thirty.

OMODELING OF FUEL CONSUMPTION IN TERMS OF ENGINE

MODEL FOR ROLLING RESISTANCE

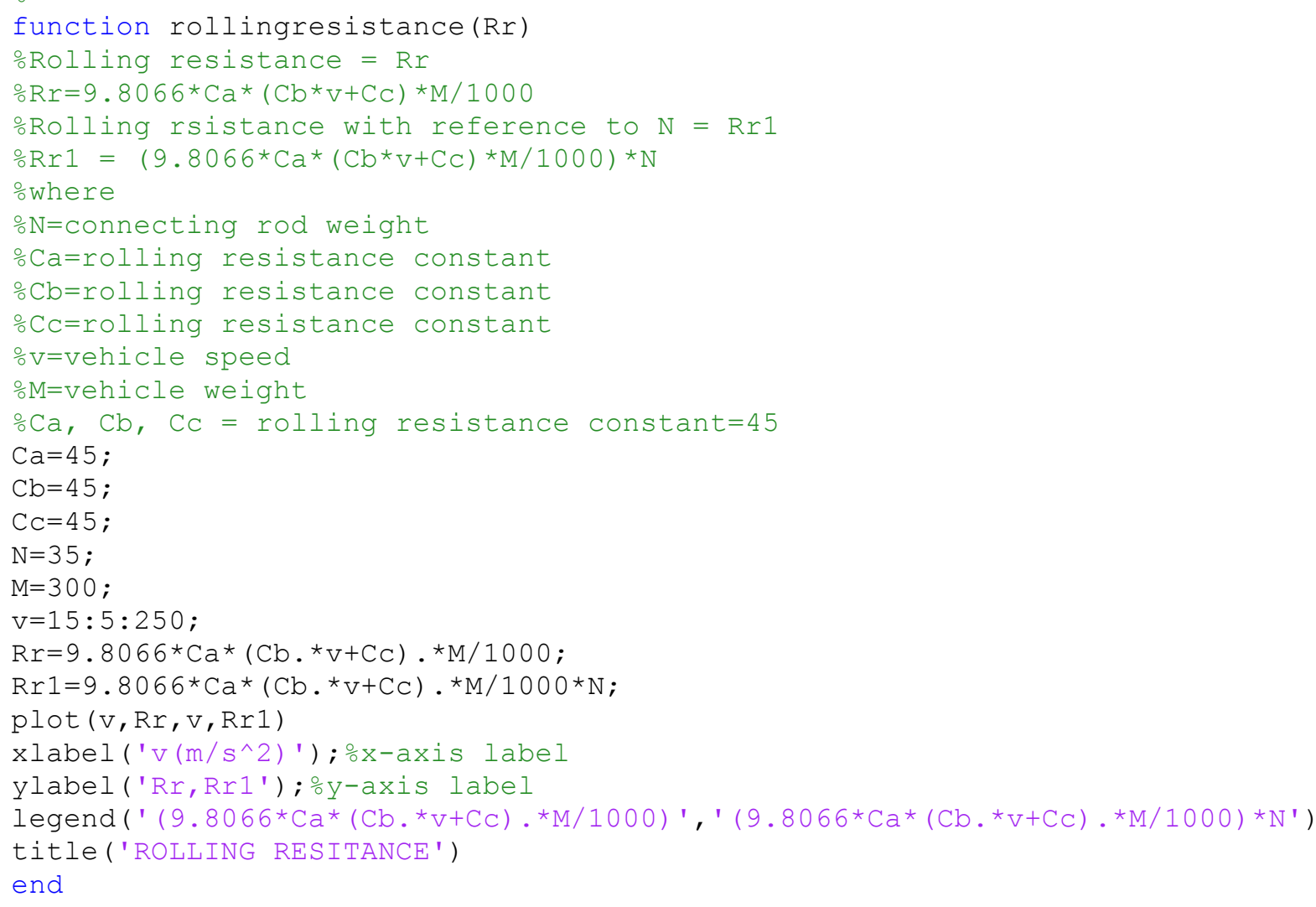

The modification of equation " $\mathrm{Rr}$ " by this research was done by incorporating $\mathrm{N}$ to form the equation "Rr1". 


\section{Simulation scheme for equation 108}

\section{SIMULATION OF THE EQUATIONS}

BEMP

e Edit View Simulation Format Tools Help

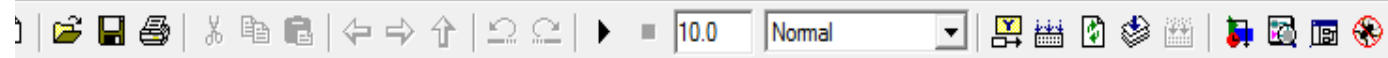

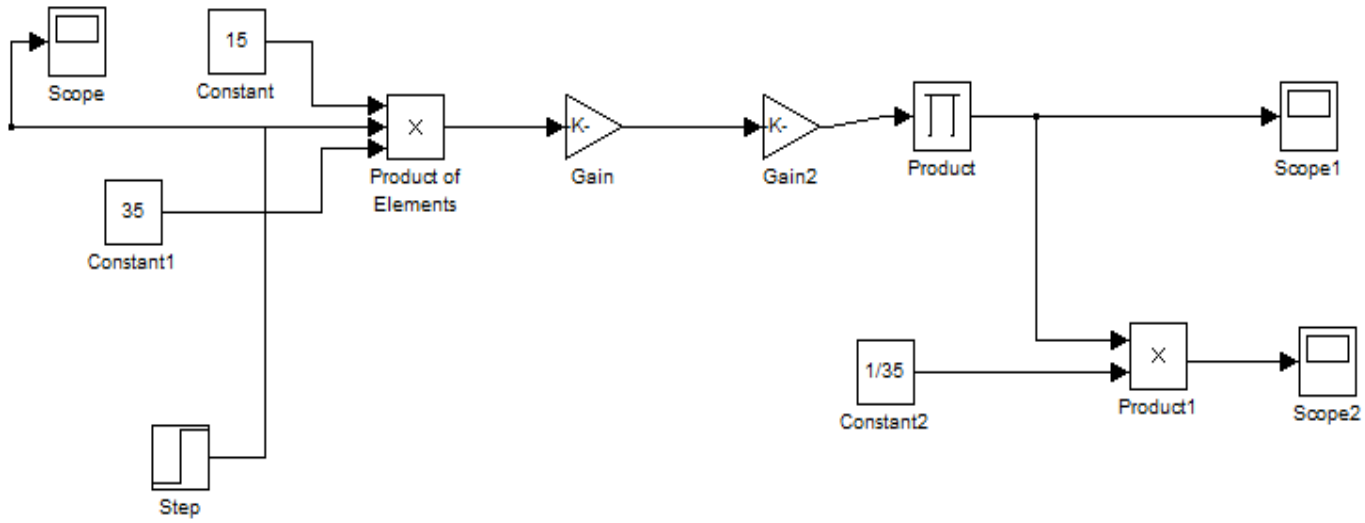

\section{Simulation scheme for equation 109}

BURNFRACTION

le Edit View Simulation Format Tools Help

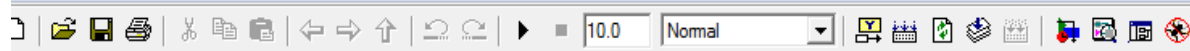

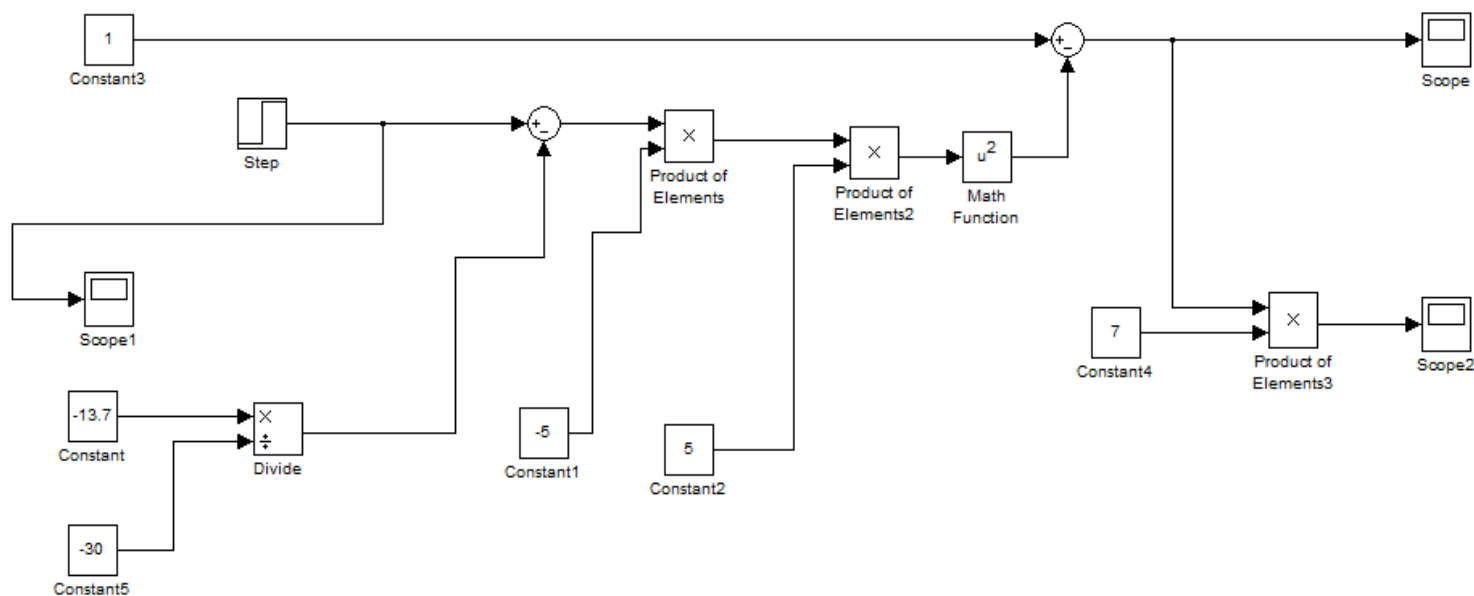

\section{Simulation scheme for equation 121}

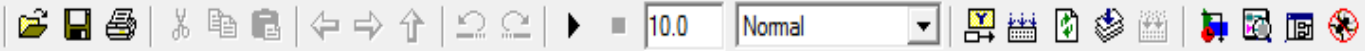

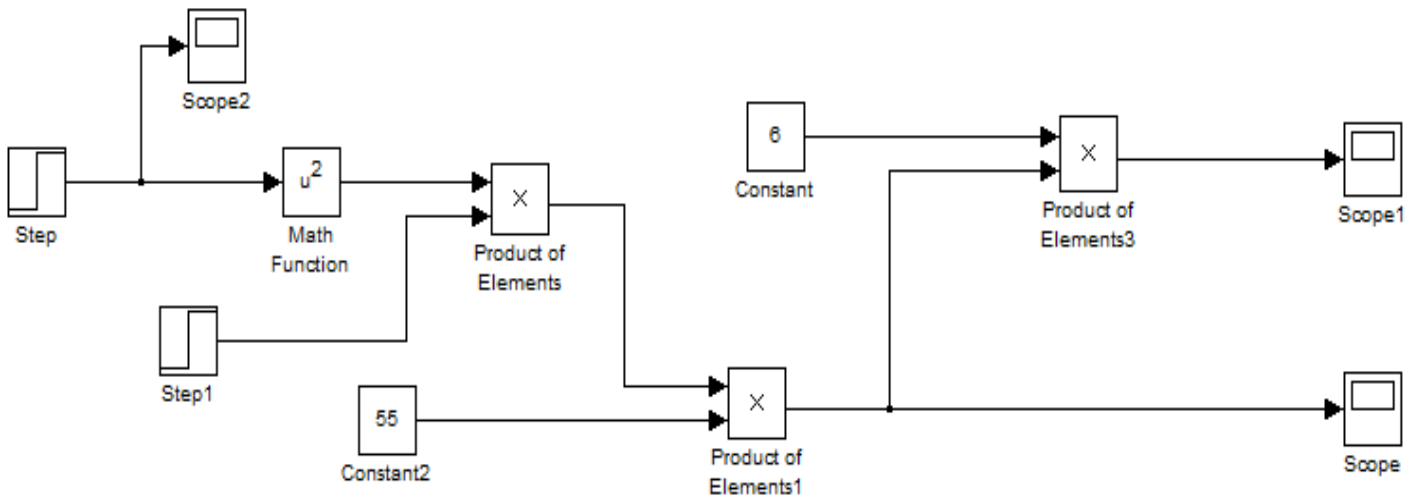




\section{Simulation scheme for equation 122}
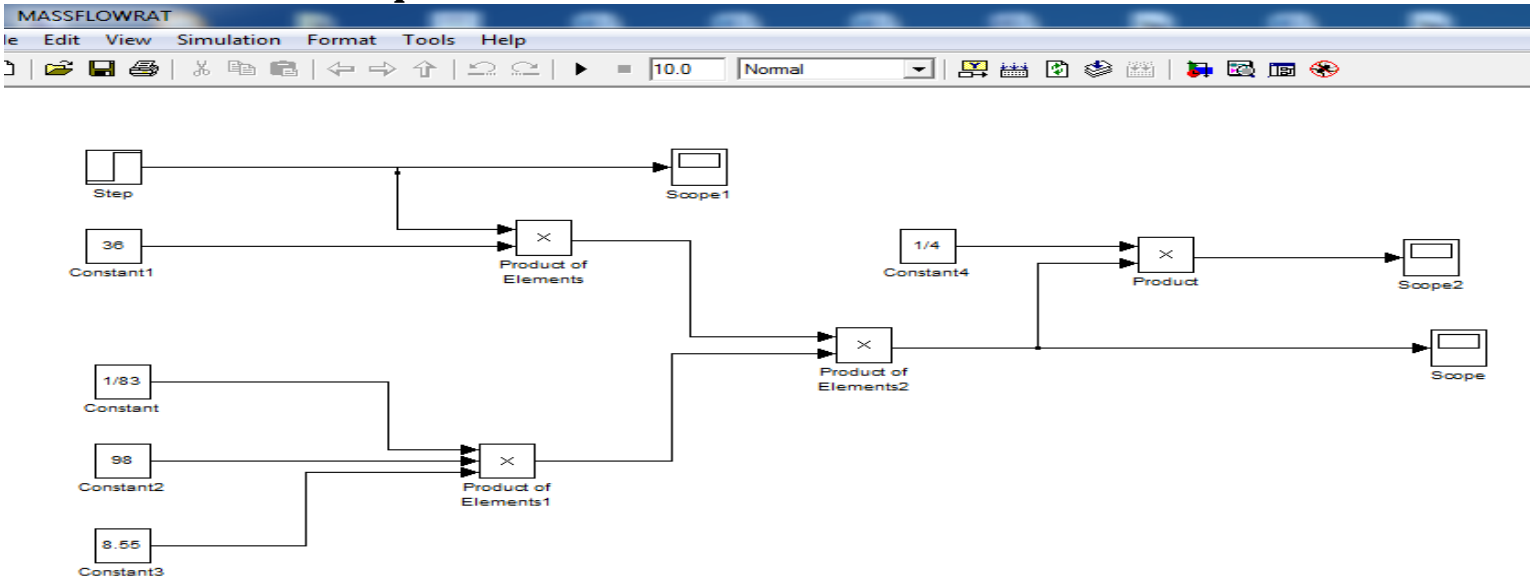

\section{Simulation scheme for equation 129}

i. PISTONVELOCIT

ile Edit View Simulation Format Tools Help

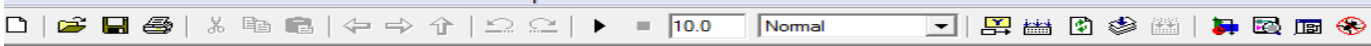

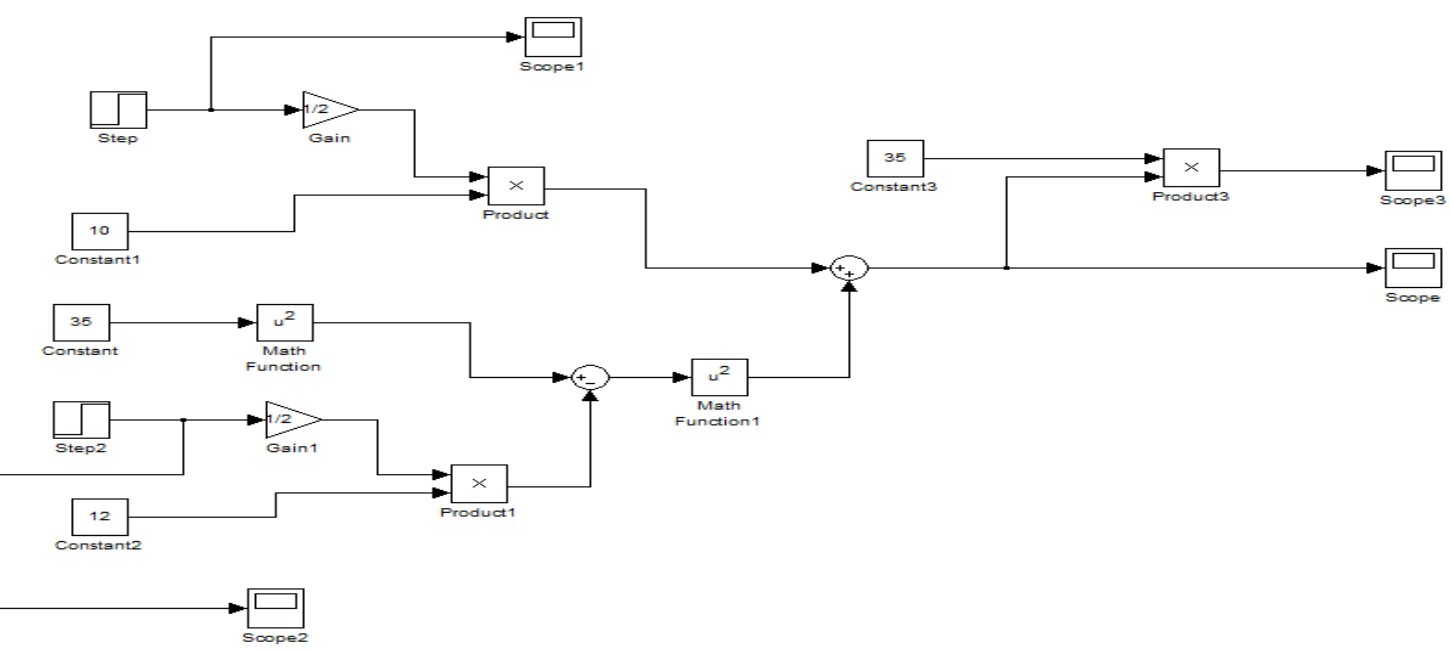

\section{Simulation scheme for equation 130}

ROLUNC

ile Edit View Simulation Format Tools Help

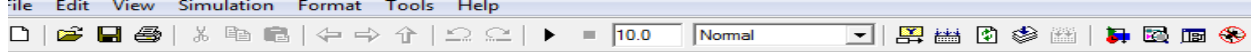

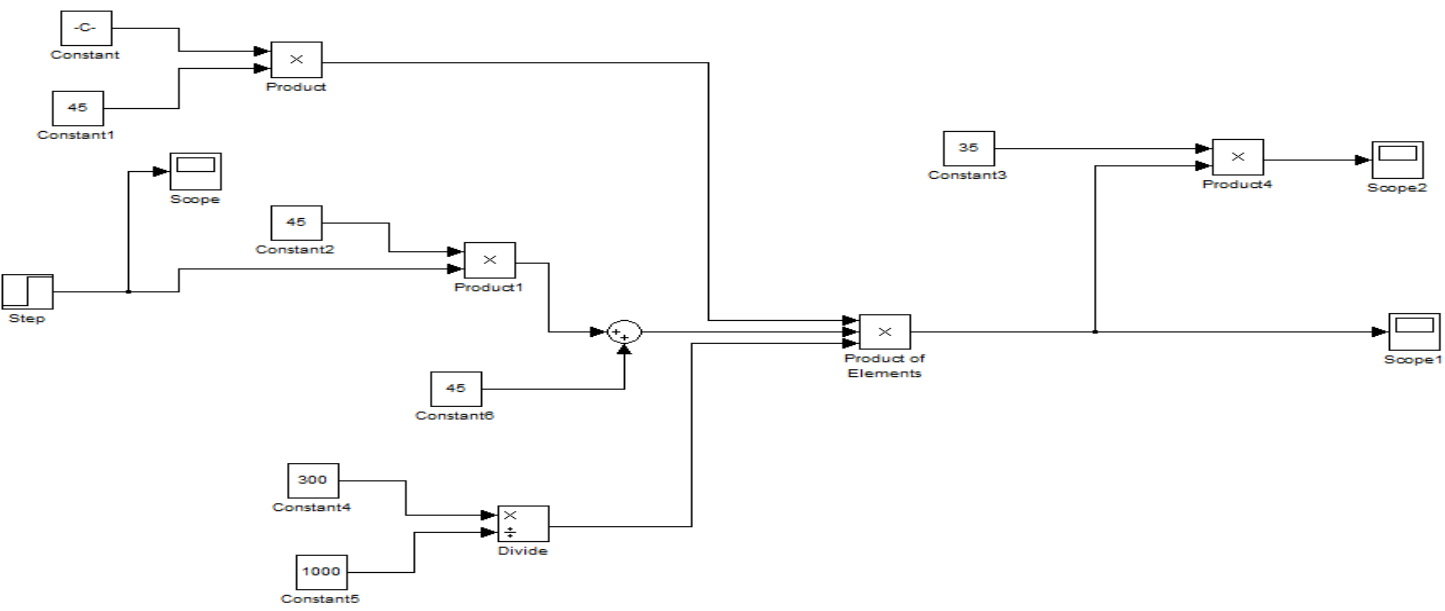




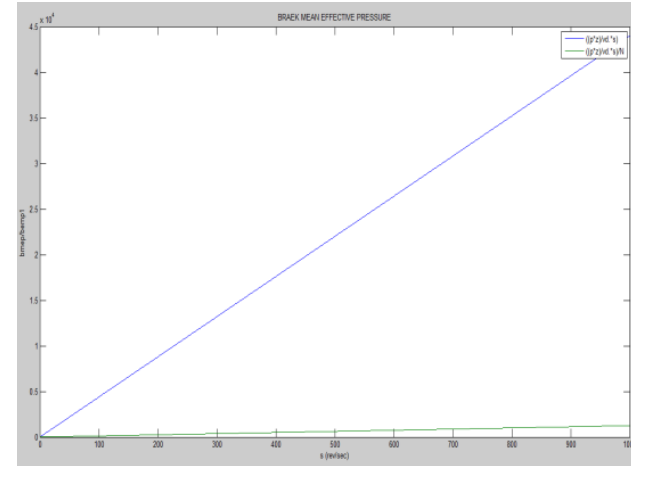

Modeling results for equation 108

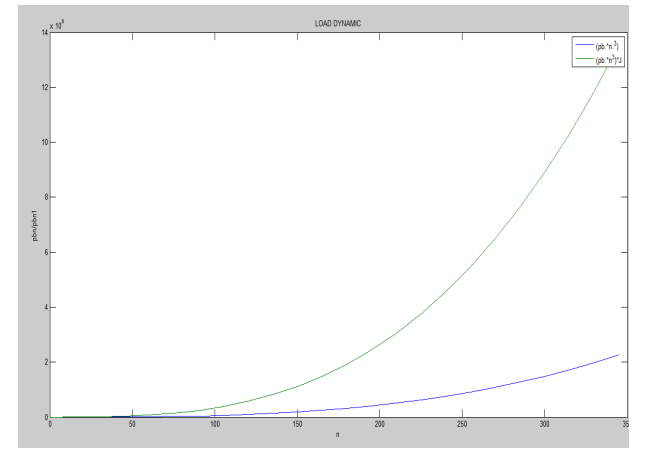

Modeling results for equation 121

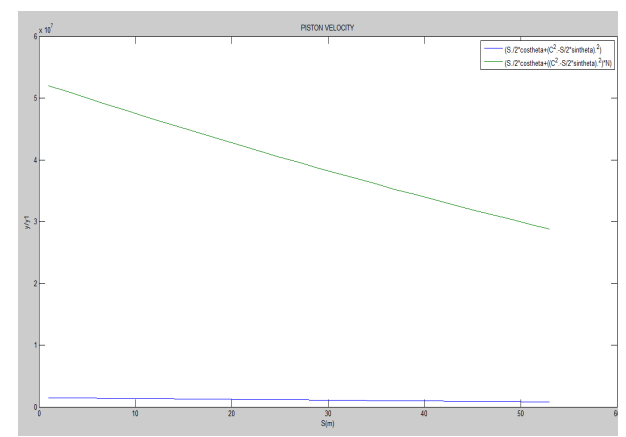

Modeling results for equation 129

\section{MODELING RESULTS}

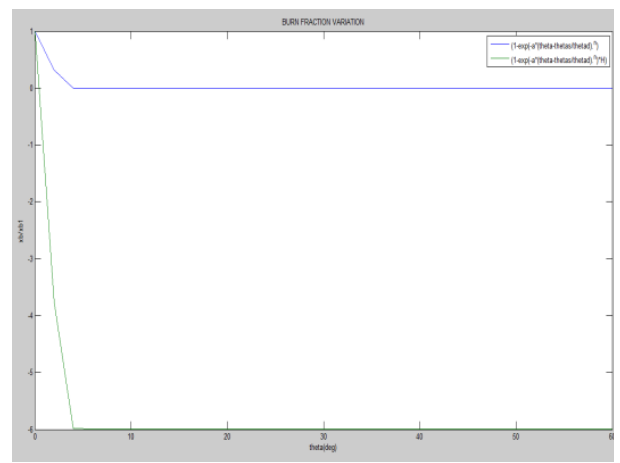

Modeling results for equation 109

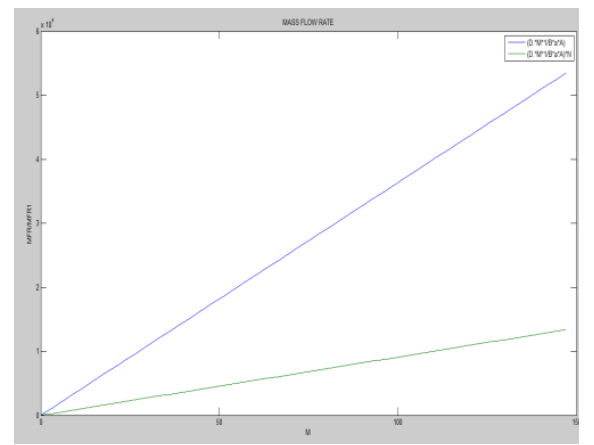

Modeling results for equation 122

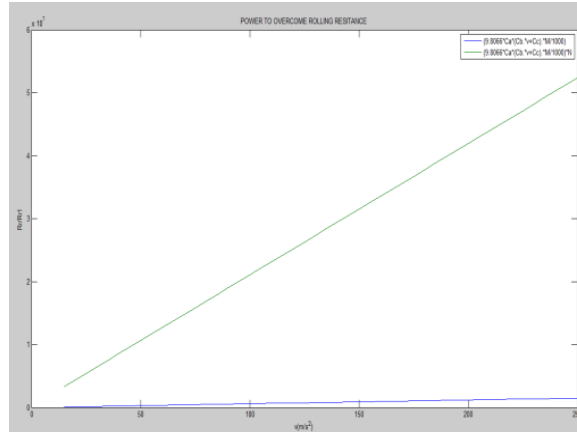

Modeling results for equation 130

\section{SIMULATION RESULTS}

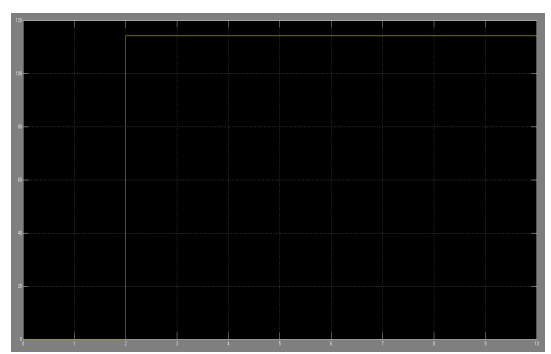

Simulation results i for equation 108

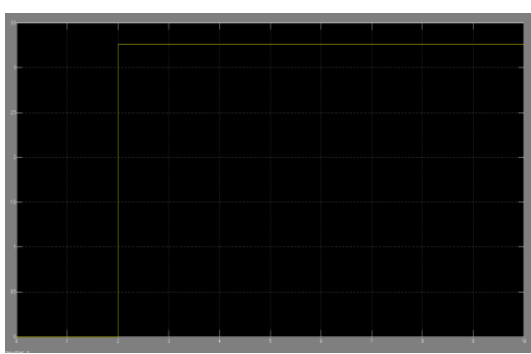

Simulation results ii for equation 108 


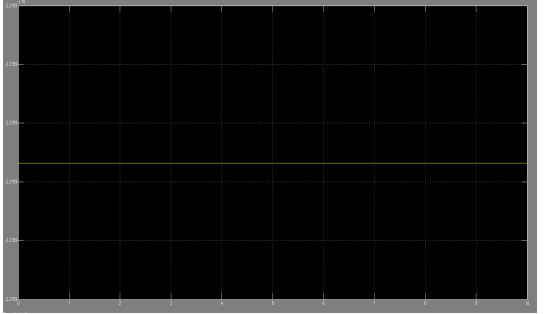

Simulation results i for equation 109

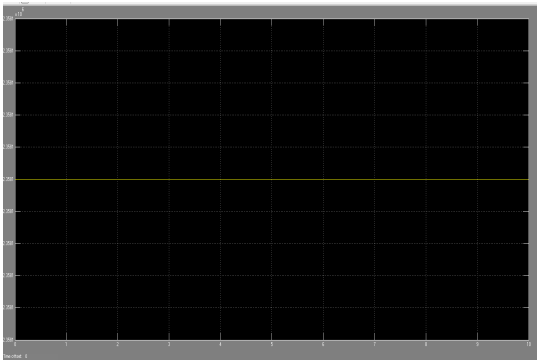

Simulation results i for equation 121

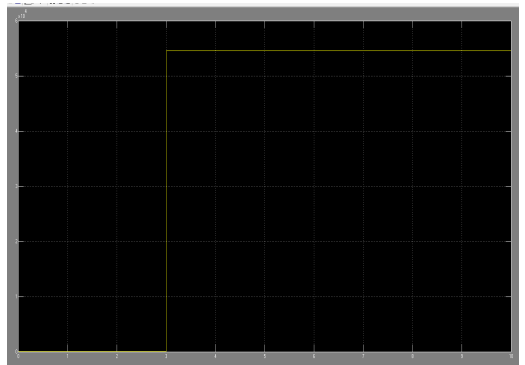

Simulation results i for equation 122

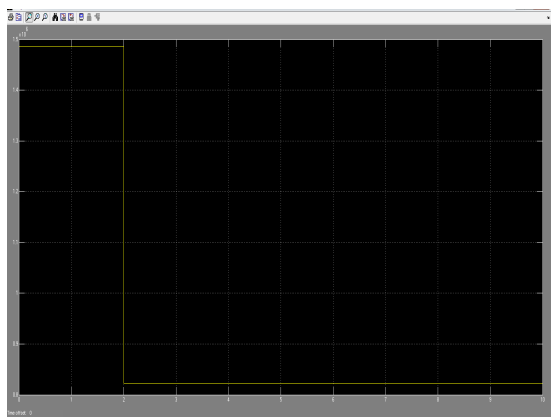

Simulation results i for equation 129

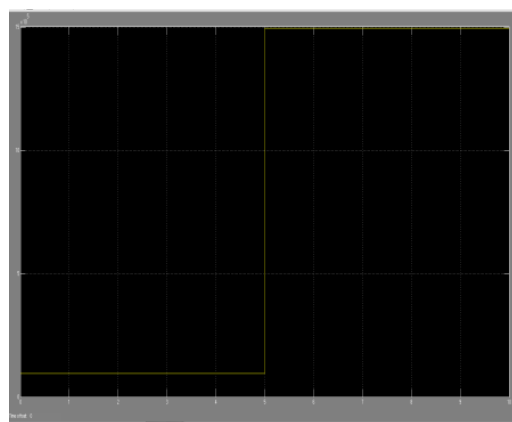

Simulation results i for equation 130

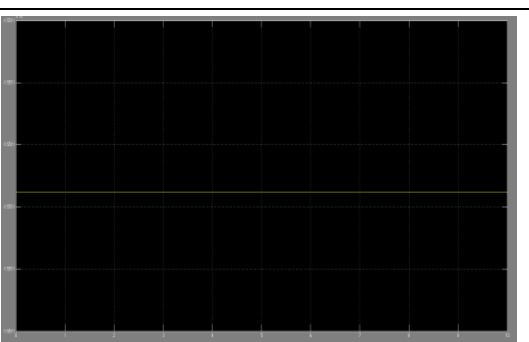

Simulation results ii for equation 109

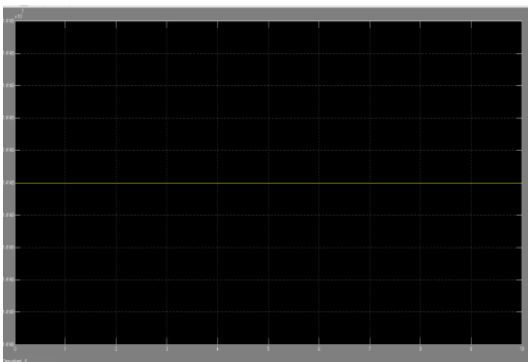

Simulation results ii for equation 121

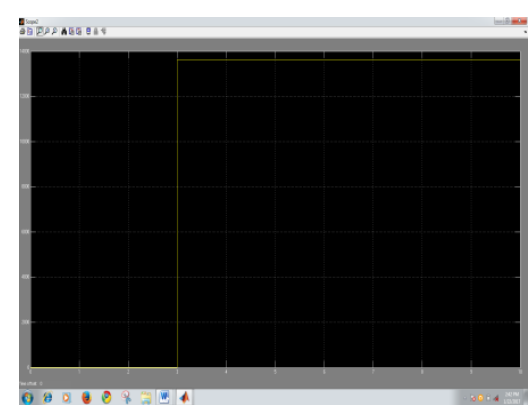

Simulation results ii for equation 122

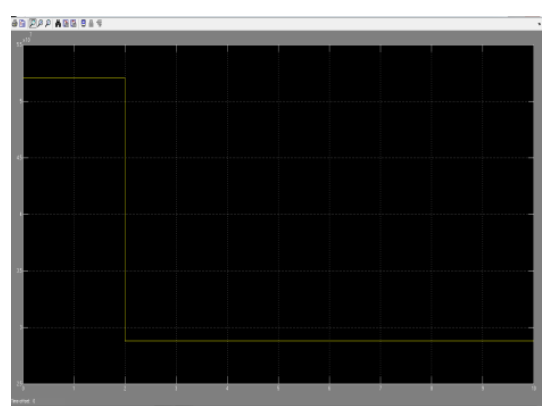

Simulation results ii for equation 129

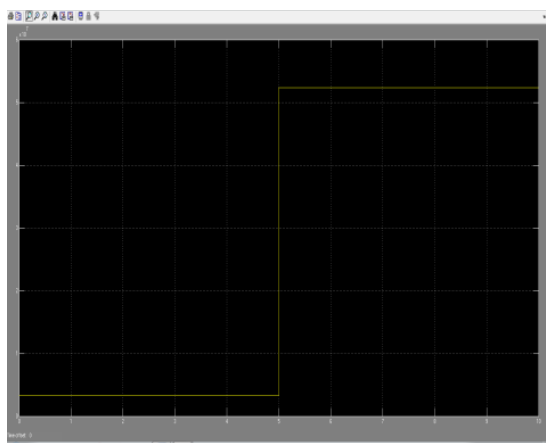

Simulation results for equation 130 


\section{ANALYSIS OF RESULTS}

Incorporating the ICE parameter values of piston diameter, number of piston rings, number of pistons, engine temperature and weight of connecting rod into the equations during modeling as well as simulation will give graphical results above. Thus, by these analyses frictional heat produce has reduced resulting to improvements in equations mentioned below. Blue lines of modeling results represent outcomes of previous authors' models whiles green lines represent remodeling with inclusion of these parameters.

As a result of reducing frictional heat by this research, the following deductions were arrived at. Thus, for equation 108 the relative mean effective pressure available has decrease which has practical implication that more power is available for motion as well as to reduce frictional heat generated. The practical implication is that rate of fuel consumption will reduce. All other conditions been equal, remodeling of equation 109 indicates frictional heat was reduced resulting to less fuel been combusted. This means policy for lesser fuel consumption is achieved whiles practically combustion rate is reduced for the same work done. Equation 121 shows that after remodeling, with the same quantity of fuel more power is produced to overcome load and pressure, thus frictional heat has been reduced in this friction model. Resulting remodeling graph for equation 122 indicates that less quantity of fuel flows for combustion, hence less fuel consumption. This is because frictional heat has been reduced after remodeling the equation. Parameter remodeling of equations 129 and 130 indicated that frictional heat was reduced and more power was produced for piston motion as well as to overcome rolling resistance respectively. Therefore, engine efficiency has been improved.

Simulation result ii for equation 108 shows increase in relative mean effective pressure which will result to lower heat generated by friction and relatively less fuel consumption. Result ii for simulating equation 109 indicates less fuel combustion which implies lesser frictional heat generation. Graph for result ii for simulating equation 121 indicates more combustion power was produced to overcome load and reduce frictional heat effect. Simulation result ii for equation 122 revealed less fuel flow resulting to less frictional heat generation. Result ii for simulating equations 129 and 130 indicated more combustion power for piston motion and rolling resistance respectively so as reduce frictional heat generation.

\section{CONCLUSION AND RECOMMENDATION.}

Heat generation due to internal combustion processes contributes towards rising rate of fuel consumption by internal combustion engines. The parameters mentioned in this research must be incorporated to reduce heat as well as rate of fuel consumption.

\section{References}

Amini, A., Mirzaei, M. and Khoshbakhti, S. R. (2013) “Optimization - base Non - Linear Control Law with Increased Robustness for Air Ratio Control in SI Engine". International of Automotive Engineering.

Bedajangam, S. K. and Jadhave, N. P. (2003). “Analysis of Frictional Characteristics of Internal Combustion Engines”. International Journal of Scientific and Research Publications. Kondhwa, India.

Cho, S., Choi, S, and Bae, C. (2000). "Frictional Modes Barrel Shaped Piston Ring Under Flooded Lubrication”. Tribology International, Volume Thirty Three (33), pp. 545 - 551.

Ganeshan, V. (2012). Internal Combustion Engines. Tata Macgraw - Hill (Publisher), New Delhi.

Gilat, A. (2004). MATLAB. An Introduction with Applications. John Wiley and Sons (Publisher).

Guzzella, L. and Onder, C. H. (2010). Introduction to Modeling and Control of Internal Combustion Engine Systems. $2^{\text {nd }}$ Edition, Springer Verlag, Berlin.

Herst, H. M. (2007). Theoretical Modeling of the Cylinder Lubrication in Internal Combustion Engine and it's Influence on Piston Slap Induced Noise Friction and Wear. PhD Thesis, Faculty of Mechanical Engineering, 
Technical University of Graz.

Law, T. (2007). The Effect of Lubrication on System Modification on Engine Friction and Thermal Behavour. PhD Thesis University of Nottingham.

Livanos, G. and Kyrtatos, N. P. (2006). "A Model of the Friction Loses in Diesel Engines". Journal for Society of Automobile Engineers, 01 - 0888.

Kanne, E. C. (2000). Engine Thermomangement for Fuel Consumption Reduction. Doctorial Thesis, Swiss Federal Institute of Technology, Zurich.

Karkamkar, A. (2013). "Effect of Spark Timing on Combustion Process of Spark Ignition Engine Using Matlab". International Journal of Computer Application.

Mufti, R. A. (2004). Total and Component Friction in a Motored and Firing Engine. PhD Thesis School of Mechanical Engineering, University of Leeds, UK, pp. 1 - 276.

Meyer, J. (2007). Engine Modeling of an Internal Combustion Engine. PhD Thesis, Ohio State University.

Priest, M. and Taylor C. M. (2002). "Lubrication of Automobile Engine Analysis”. Elsevier Science Journal.

Rupp, D. (2009). Model - based Adaptive Air/Fuel Ratio Control for Automotive Gasoline Engine. PhD Thesis, ETH, Zurich.

Saris, M. and Philips, N. (2005). "Computer Simulation Engine Performance”. University of Pennsylvania Press.

Sahoo, B. B. (2011). Clean Development Mechanism Potential of Compression Ignition Diesel Engines Using Gases in Dual Fuel Mode PhD Thesis, Centre for Energy, IIT Guwahati, India.

Samhaber, C., Wimmer, A. and Liobner, E. (2012). "Modeling of Engine Warm - up with Integrating of Vehicle and Engine Cycle Simulation". Journal for Society of Automobile Engineers, 011679.

Sandoval, D. and Heywood, J. (2003). "An Improved Friction Model for Spark Ignition Engines”. Journal for Society of Automobile Engineers.

Tan, Y. C. and Ripin, Z. M. (2011). "Frictional Behavour of Piston Rings of Small Utility Two Stroke Engine under Secondary Motion of Piston". Tribology International, Volume 44, pp. 592 - 602.

Tamminen J., Sandstroma, C. E. and Anderson, P. (2006). "Influence of Load on the Tribological Conditions in Piston Rings and Cylinder Liner Contacts in a Medium - Speed Diesel Engines". Tribology Iinternational, pp. 1634 $-1652$.

Yildiz, Y., Annaswamy, A., Yanakiev, D. and Kolmanovsk, I. (2010). “Spark Ignition Engine Fuel/Air Ratio Control: An Adaptive Control Approach". Control Engineering Practice, 18(12), pp. 1369 - 1378.

Yue, H. (2008). Mesoscopic Fuel Consumption and Emissions Modeling. PhD Dissertation. Virginia Polytechnic Institute and State University.

Zammit, J - P. (2013). Managing Engine Thermal State to Reduce Friction Losses During Warm - up. PhD Thesis, University of Nottingham.

Zoz, S., Strepek, S., Wiseman, M. and Qian, C. (2001). “Engine Lubrication System Model for Sump Oil Temperature Prediction". Journal for Society of Automobile Engineers. 01 - 1073. 